\title{
Peracangan Kemasan makanan Ringan Kacang Sihobuk Produksi “UD. TADODO" sebagai Media promosi
}

\author{
Rommel Sinaga, Sahban Simangunsong \\ Program Studi Desain Grafis Politeknik Negeri Media Kreatif \\ rosinaga24@gmail.com
}

\begin{abstract}
ABSTRAK
Beberapa tahun belakangan ini perkembangan dunia bisnis mengalami kemajuan yang cukup pesat, untuk dapat bertahan perusahaan harus mempunyai solusi pemasaran yang efektif salah satunya dengan cara melakukan suatu perancangan desain kemasan.

Kemasan secara tidak langsung sangat berpengaruh dalam sebuah pemasaran produk karena kemasan tidak hanya sebagai profesinalitas perusahaan, bahkan kemasan juga dijadikan sebagai suatu branding/identitas perusahaan untuk meningkatkan minat pembeli.

Bagaimana cara merancang kemasan kacang sihobuk olahan ud. TADODO agar menjadi suatu identitas perusahaan dan mampu menjadi solusi dalam pemasaran. Dengan adanya perancangan kemasan, masyarakat akan mengenal ud. TADODO sebagai usaha yang memproduksi kacang sihobuk sehingga meningkatkan minat pembeli.

Kata Kunci : Perancangan, Kemasan, ud. TADODO, Kacang Sihobuk
\end{abstract}

\section{ABSTRACT}

In recent years the development of the business world has progressed quite rapidly, in order to survive the company must have an effective marketing solution, one of which is by doing a packaging design. Indirect packaging is very influential in a product marketing because packaging is not only a company's professionalism, even packaging is also used as a branding / corporate identity to increase buyer interest.

How to design packaging for processed yakobuk beans. TADODO in order to become a corporate identity and be able to become a solution in marketing. With the packaging design, people will get to know UD. TADODO as a business that produces sihobuk beans thus increasing buyer interest.

Keywords: Design, Packaging, UD. TADODO, Sihobuk Beans

\section{PENDAHULUAN}

Indonesia memiliki beragam kebudayaan, dan kebudayaan tersebut menjadi modal dan daya tarik wisata yang unik dan menarik sehingga harus dipelihara dan dilestarikan, kacang sihobuk merupakan salah satu makanan ringan khas daerah dingin Tarutung Tapanuli Utara.

Sihobuk merupakan salah satu nama desa yang ada di Tarutung, dan akibat dari sebuah bencana desa Sihobuk ini menjadi porak-poranda. Untuk mengenang kejadian tersebut masyarakat lalu memasak kacang dan kacang tersebut dinamai kacang 
sihobuk yang kini namanya telah tersiar kemana-mana bahkan sampai mancanegara. Pada awalnya masyarakat di desa Sihobuk yang memang mayoritas petani, membuat kacang sihobuk hanyalah untuk dimakan saja. Namun seiring waktu berjalan, masyarakat di desa Sihobuk mulai memikirkan untuk mengelolanya dan menjadikan kacang sihobuk komiditas pencarian. Hal ini dapat kita lihat banyaknya sekarang para penjual kacang sihobuk di pesisir jalan di sekitar Tarutung, bahkan sampai ke beberapa kota di SUMUT.

Proses pembuatan Kacang Sihobuk dapat dikatakan cukup unik walaupun memakan waktu yang cukup lama, awalnya kacang-kacang dipilih kemudian kacang tersebut di rendam biasanya direndam selkitar 2 hari, selanjutnya dilakukan penjemuran, kemudian barulah kacang di gongseng dengan media pasir yang memakan waktu 1-1,5 jam

Kemasan mempunyai fungsi sebagai media promosi, yang mana kemasan dibuat untuk mendapatkan simpati dan daya tarik perhatian dari komsumen. Oleh karena itu, kemasan harus dipikirkan, dirancang, dan didesain dengan baik. Pentingnya kemasan membuat para pengusaha rela mengeluarkan tambahan biaya exstra dalam aktifitas pemasaran ditambah pesatnya ilmu pengetahuan dan tehnologi memberikan pengaruh positif dalam bidang usaha sehingga banyak cara yang digunakan dalam memasarkan dan mempromosikan produk yang dijual.

Kemasan telah menjadi salah satu titik kombinasi dari proses di dalam sebuah wadah yang biasa di gunakan yaitu drum yang terbuat dari besi yang dimana apinya bersumber dari kayu bakar. Proses pembuatan secara traditional inilah yang menjadikan kacang sihobuk memiliki karakter cita rasa yang khas menjadikan kacang ini berbeda dari kacang-kacang lainnya.

Kacang Sihobuk sendiri sudah mendunia yang mana orang yang berkunjung ke daerah Tapanuli baik yang dari luar kota maupun luar negeri, akan merasa kurang abdol bila tidak membeli makanan ringan kacang sihobuk ini sebagai oleh-oleh dari daerah Tapanuli, yang terkenal gurih, renyah dan nikmat. Kacang sihobuk merupakan pilihan alternatif oleh-oleh yang harus dibawah dari Tapanuli Utara. Kemasan kacang sihobuk berupa plastik transparan warna putih dengan label brand kacang sihobuk berwarna merah polos.

Pemasaran (self service) yaitu memberikan ciri-ciri produk untuk menyakinkan komsumen, ini merupakan salah satu ilmu pemasaran. Kemasan yang menarik dan baik membuat mindset komsumen berubah dan beralih ke produk lain yang mempunyai jenis produk yang sama, jadi kemasan dapat menciptakan opini keyakinan komsumen terhadap perusahaan (brand image) dan inovasi peluang (innovation opportunity).

Desain kemasan Kacang Sihobuk ud. TADODO dirasa masih kurang, maka perlu dilakukan re-design kemasan. Saat ini, kemasan yang digunakan oleh ud. TADODO adalah kemasan biasa dan yang umum dijual di toko atau gerai kacang sihobuk. Kemasan kacang sihobuk 
menggunakan plastik sederhana dengan label merk di dalam kemasan. Oleh sebab itu, penulisan karya ilmiah ini dilakukan agar dapat membangun

\section{METODOLOGI PENELITIAN}

Metodologi yang akan penulis gunakan dalam pembuatan perancangan desain artwork pada produk merchandise adalah pengkajian atas berbagai hasil analisis kualitatif deskriptif melalui 3 tahapan utama, yakni; identifikasi, wawancara, dan kepustakaan :

Penulis melakukan penelitian langsung ke tempat melakukan Tugas Akhir sehingga penulis dapat melakukan gambaran tentang geografis daya minat perilaku terhadap daya beli dan culture budaya setempat. Observasi adalah pengamatan langsung kepada suatu objek yang akan diteliti. Dalam metode ini dilakukan peninjauan dan pengamatan secara langsung dan segala hal yang berhubungan dengan masalah yang dibahas. Observasi dilakukan dengan cara pengamatan beberapa state atau toko-toko yang menjual kacang sihobuk, data yang didapatkan kemudian dicatat dan dikumpulkan sebagai data dalam melakukan penyusunan Tugas Akhir ini.

\section{Penulis mengadakan} wawacara dan diskusi dengan pihakpihak yang berhubungan dengan objek penelitian, terutama tentang desain dan asal usul produk secara rinci dengan mengumpulkan datadata yang akurat tentang imformasi produk tersebut. Wawancara didefinisikan sebagai percakapan yang diarahkan untuk topik tertentu, citra kacang sihobuk produksi ud. TADODO sebagai salah satu pilihan/alternatif oleh-oleh khas dari TAPUT.

interaksi antara pewawancara dan pemilik usaha akan memberikan kontribusi yang sangat berarti dalam proses pengumpulan data.

\section{HASIL DAN PEMBAHASAN}

Konsep desain yang ingin dituangkan berupa kemasan yang lebih inovatif sesuai dengan perkembangan zaman dengan penggunaan warna CMYK. Konsep desain merupakan desain 2 dimensi dengan warna yang disesuaikan dengan culture budaya Tapanuli tujuan visualisasi perancangan kemasan adalah untuk mempengaruhi minat dan perilaku komsumen untuk membeli produk kacang sihobuk olahan ud. TADODO sehingga nantinya dapat meningkatkan grafik penjualan. Hasil dari perancangan ini berupa beberapa media promosi seperti $\mathrm{x}$ - banner yang berpungsi untuk memberi imformsi tentang kacang sihobuk, paper bag berguna untuk sebagai promo atau penarik dengan desain paper bag maka komsumen akan merasa di layani dengan baik, mup dan label produk.

\section{Kemasan}

Meskipun sudah mempunyai kemasan namun belum mempunyai desain yang menjadi comperate identity sendiri.

2. Media dan Aplikasi

Pada media-media promosinya ud. TADODO masih belum efektif hanya merk dagang hanya di dalam tokoh sehingga orang atau komsumen tidak 
mengetahui asal muasal dan produsen kacang sihobuk itu sendiri.

Logo dari kacang sihobuk sebenarnya sudah ada namun masih kurang menarik hanya menggunakan satu warna saja sehingga dilakukan perubahan logo tanpa merubah brand image produk tersebut.

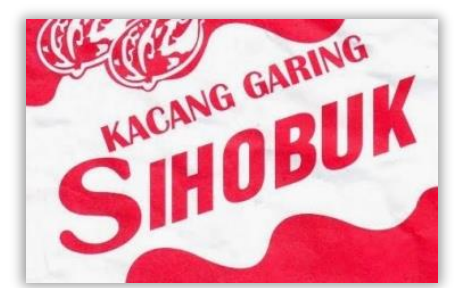

Gambar. Brand Logo Kacang Sihobuk Yang Lama

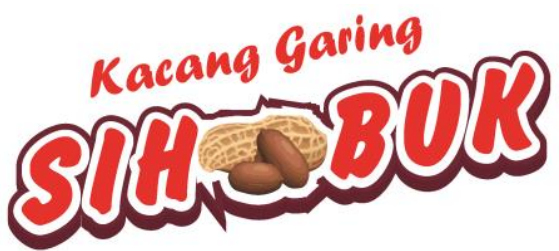

Gambar.Brand Logo Kacang Sihobuk Hasil Desain

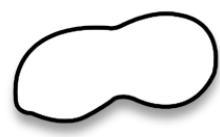

Gambar. Outline Kacang

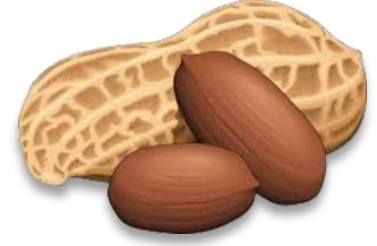

Gambar. Vector Kacang

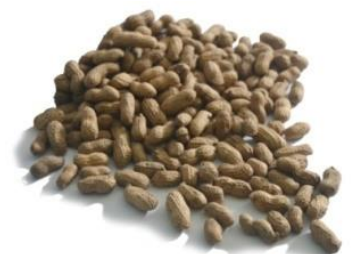

Gambar Hasil Photografi Kacang Sihobuk

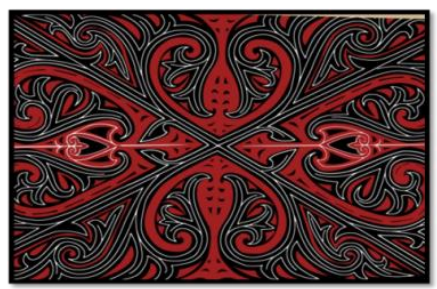

Gambar. 4.2.2.4. Oranament Gorga Batak

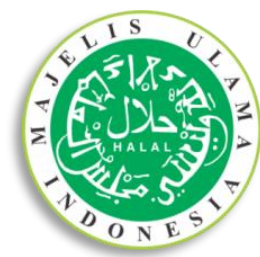

Gambar. Logo Halal Majelis Ulama Indonesia

Sketsa desain adalah penerapan elemen-elemen desain dengan berbagai media yang diterapkan nantinya akan dipergunakan dalam acuan standarisasi perancangan visual desain sebagai promosi dan media yang digunakan seperti Low Density PolyEthylene (kemasan plastik), paper bag, stiker haires dan poil. Proses sketsa umumnya hitam putih dibuat dengan coretan atau gambaran pensil. Berikut ini beberapa sketsa desain yang dibuat berdasarkan objek yang dipilih sesuai media yang diterapkan :

Tahapan dalam proses perancangan kemasan mencari beberapa referensi dari berbagai unsur atau media imformasi lainnya sebagai pengembangan ide. Dengan menggunakan sofwere desain Adobe Photoshop dan Adobe Illustrator Cs 6 . 


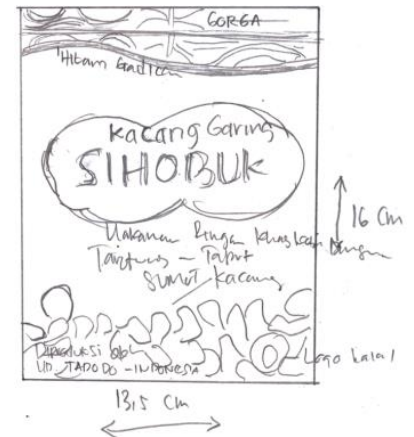

Gambar. Sketsa Desain Label Kacang Sihobuk
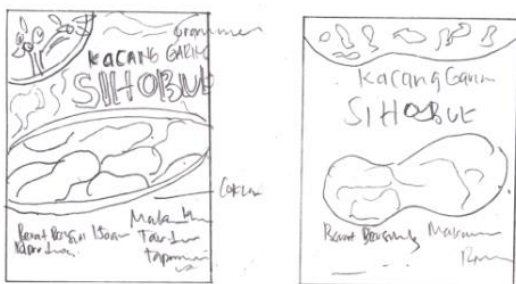

Gambar..Sketsa Desain Label Kacang Sihobuk Alternative Lain

\subsubsection{Proses Perancanngan Desain} Digital.

Perancangan Brand Image/ Merk

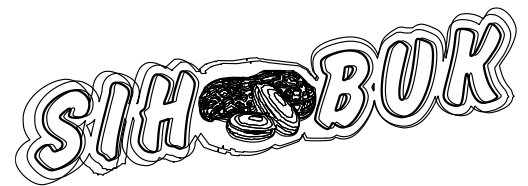

Gambar. Hasil Desain Brand Logo Sihobuk Secara Outline

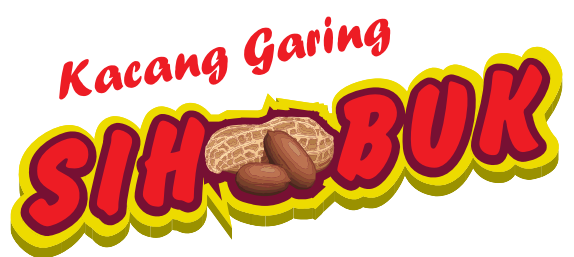

Gambar. Hasil Desain Brand Logo Kacang Sihobuk Yang Baru

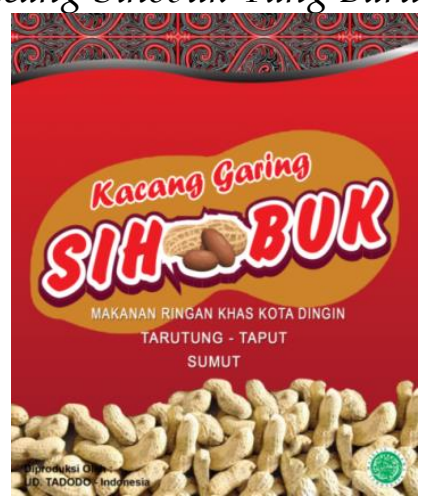

Gambar. Desain Label Kemasan Plastik

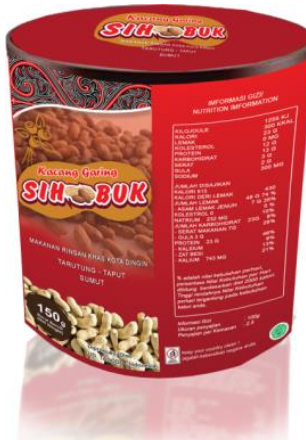

Gambar. Ilustrasi Desain Pada Media Kaleng

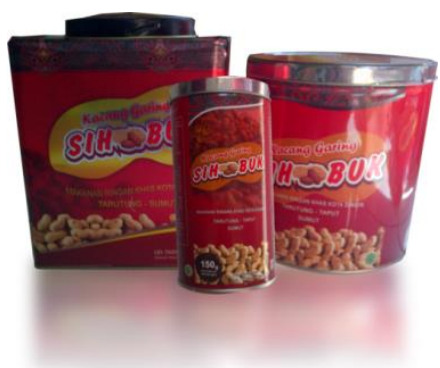

Gambar Hasil Desain Label Stiker Pada Media Kaleng

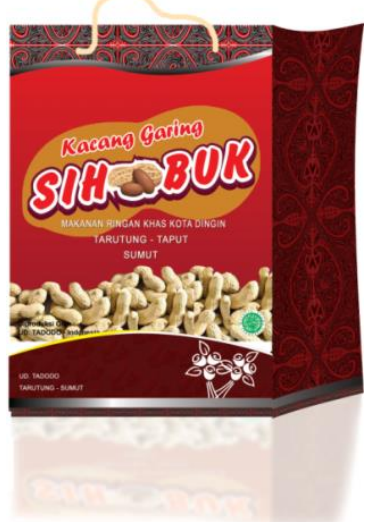

Gambar. Ilustrasi Paper Bag

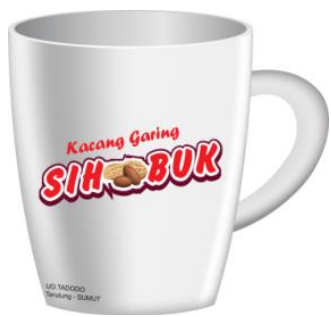

Gambar. Stasionery Desain Mug 


\section{KESIMPULAN}

Setelah melakukan proses perancangan desain kemasan kacang sihobuk home industry ud. TADODO, maka terbentuklah beberapa kesimpulan dari penulis. Kesimpulan tersebut merupakan hasil akhir penyelesaian rumusan masalah yang ada. Adapun kesimpulan-kesimpulan tersebut sebagai berikut:

1. Kemasan sangat berpengaruh dalam sebuah pemasaran produk karena kemasan tidak hanya sebagai pembukus produk atau sekedar wadah produk, karena kemasan juga sebagai identitas dan sebagai penarik perhatian konsumen agar membeli produk tersebut. Dengan adanya perancangan kemasan ini diharapkan mampu menjadi suatu identitas perusahaan untuk meningkatkan minat pembeli.
2. Hasil akhir yang didapat dari seluruh proses perancangan yang penulis lakukan adalah berupa desain kemasan dan beberapa media promosi Kacang sihobuk ud.TADODO yang bisa digunakan sebagai profesionalitas perusahaan.

Dari perancangan desain kemasan ud.TADODO, penulis mempunyai saran, Adapun saran-saran yang ingin disampaikan oleh penulis antara lain: 1. Bagi Perusahaan ud. TADODO a. Ud.. TADODO harus membuat revesioner untuk perubahan dalam sistem bisnis yang sehat dan berinovasi dalam memperoleh segmentasi pasar.

b. Perusahaan harus lebih memperhatikan desain kemasan agar mampu menjadikan kemasan sebagai suatu identitas perusahaan agar tidak mudah di klaim oleh pihak lain. 


\section{DAFTAR PUSTAKA}

Ladjamudin Al-Bahra. 2015.

Analisis dan Desain Sistem

Informasi.

Yogyakarta: Graha Ilmu

Purwanto, Bambang. (2007).

Tata letak dan

typografi dalam

desain grafis. Pusat

grafika indonesia

kerjasama dengan

LPMG-ATG

TRISAKTI : hal.72.

Pujiriyanto. 2005. Desain Grafis

Komputer. Yogyakarta: Andi

Publisher

Sitepu, Vincensius

(2001).Panduan

Mengenal Desain

Grafis. Jakarta barat :

Computer art.

Elemen dan prinsip desain

https://sulartopo.wordpress. com/2013/10/11/elemendesain-grafis.html (Diakses pada 3 juli 2015)
Elemen desain

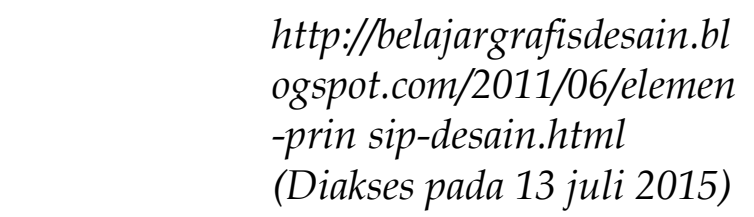

Desain kemasan

http://aankhumaeroh.blogsp ot.com/2013/04/pengertiankem asanperankemasan.html (Diakses 14 juli 2015)

Prinsip \& unsur desain grafis https://tyasjenitri.wordpres s.com/2013/02/26/prinsipunsur-desain-grafis/html diakses pada 4 juli 2015)

Psikologi warna https://ml.scribd.com/doc/2 9532813/PSIKOLOGIWARNA. html (Diakses pada 7 juli 2015)

Unsur-unsur desain grafis https://alvin5550.wordpress .com/2010/09/02/nirmanadalam-desain-grafis 